\title{
Finite element simulation of RC beams under flexure strengthened with different layouts of externally bonded fiber reinforced polymer (FRP) sheets
}

\section{Simulación de elementos finitos de vigas de hormigón armado bajo flexión, reforzadas con diferentes configuraciones de láminas de polímeros reforzadas con fibras externamente adheridas}

Muhammad Umair Saleem (Main and Corresponding autor)

College of Engineering, Department of Civil and Environmental Engineering, King Faisal University 31982, Al-ahsa (Saudi Arabia)

mmsaleem@kfu.edu.sa

\section{Nauman Khurram}

Department of Civil Engineering, University of Engineering and Technology Lahore Department of Civil Engineering, University of Engineering and Technology Lahore, P.O. Box 54890, G.T. Road Baghbanpura, Lahore (Pakistan)

nauman@uet.edu.pk

\section{Muhammad Nasir Amin}

College of Engineering, Department of Civil and Environmental Engineering, King Faisal University 31982, Al-ahsa (Saudi Arabia)

mgadir@kfu.edu.sa

\section{Kaffayatullah Khan}

College of Engineering, Department of Civil and Environmental Engineering, King Faisal University 31982, Al-ahsa (Saudi Arabia)

kkhan@kfu.edu.sa

Manuscript Code: 992

Date of Acceptance/Reception: 25.09.2018/25.10.2017

DOI: $10.7764 /$ RDLC.17.3.383

\begin{abstract}
Current research work is aimed to numerically simulate the failure behavior of Fiber Reinforced Polymer (FRP) strengthened reinforced concrete beams having different FRP reinforcement ratios. Required objectives are achieved by performing a series of bending tests on RC beams carrying different FRP layout and FRP reinforcement ratio. Tested beams were numerically simulated by using a Finite Element Method based computer package. The layouts of the FRP strengthening were decided based upon the FRP reinforcement ratios ranging from fully wrapped beams to the beams having significantly lower FRP reinforcement ratios. Tests results are presented in the form of load-deflection curves for all of the beams and a comparison of different beam strengthening schemes is also presented. Failure patterns of RC beams strengthened with different layouts of externally bonded FRP sheets were also compared. Results of flexural tests on twelve beams specimens and numerical simulation have indicated that CFRP and GFRP can significantly increase the bending and shear strength of retrofitted beams. However, the use of higher FRP reinforcement ratios to get higher strength increment is not advisable as epoxy properties and concrete surface quality plays a vital role to increase flexural and shear strength.
\end{abstract}

Keywords: Fiber Reinforced Polymer, strengthening, finite element modelling, flexural behavior, numerical simulation.

\begin{abstract}
Resumen
El trabajo de investigación actual tiene como objetivo simular numéricamente el comportamiento de falla de las vigas de concreto reforzado fortificado con polímero reforzado con fibra (FRP) que tienen diferentes relaciones de refuerzo de FRP. Los objetivos requeridos se logran al realizar una serie de pruebas de flexión en vigas RC que tienen diferentes diseños de FRP y relación de refuerzo de FRP. Las vigas probadas se simularon numéricamente utilizando un paquete de computadora basado en el método de elementos finitos. Los diseños del refuerzo de FRP se decidieron en función de las relaciones de refuerzo de FRP que van desde las vigas totalmente envueltas hasta las vigas que tienen relaciones de refuerzo de FRP significativamente más bajas. Los resultados de las pruebas se presentan en forma de curvas de desviación de carga, para todas las vigas, y también se presenta una comparación de los diferentes esquemas de refuerzo de las vigas. También se compararon los patrones de falla de las vigas RC reforzadas con diferentes diseños de hojas FRP unidas externamente. Los resultados de las pruebas de flexión en especímenes de doce vigas y simulación numérica han indicado que CFRP y GFRP pueden aumentar significativamente la resistencia a la flexión y al corte de las vigas modificadas. Sin embargo, el uso de relaciones de refuerzo de FRP más altas para obtener un mayor incremento de la resistencia no es recomendable, ya que las propiedades epóxicas y la calidad de la superficie del concreto desempeñan un papel vital para aumentar la resistencia a la flexión y al corte.
\end{abstract}


Building inventory of the developed countries reserves a huge number of concrete buildings, ranging from small residential houses to skyscrapers and towers. Most of these structures are experiencing weathering issues due to the harsh climate, deicing chemicals, saltwater and extreme temperature changes. Many of the old concrete houses, bridges and buildings were constructed using obsolete design codes. All these aforementioned aspects make it necessary to strengthen the existing structure as these concrete structures are carrying people's lives and resources. There are many ways of strengthening concrete structures. One is by using Fiber Reinforced Polymer (FRP) or also known as Fiber Reinforced Plastics. In the past three decades many researchers have proved the suitability of FRP material for concrete and masonry structures (Sulaimani, Shariff, Basanbul, Baluch, \& Ghaleb, 1994; Chajes, Jansuska, Mertz, Thomson \& Finch, 1995; Triantafillou 1998; Triantafillou \& Antonopoulos, 2000; Khalifa, \& Nanni, 2000: Chen \& Teng, 2003, Deniaud, \& Cheng, 2004; Eshwar, Nanni, \& Ibell, 2008; Saleem, Numada, Amin, \& Meguro, 2015). FRP is made from polymeric fiber. Carbon Fiber Reinforced Polymer (CFRP), Aramid Fiber Reinforced Polymer (AFRP), Glass Fiber Reinforced Polymer (GFRP) and Basalt Fiber Reinforced Polymer (BFRP) are four types of FRP which are most commonly used for strengthening purposes. These FRP's have applications such as in aerospace, automotive, marine, construction of bridges and plastic industries. These are the composite materials made from different fibers and epoxies. FRP can increase the strength of a concrete structure up to five or six times compared to normal concrete structure (Saleem, Numada, Amin, \& Meguro, 2016). FRP gains its strength by epoxy, which is a special glue that makes a bond with the concrete. FRP can protect concrete structures from different types of cracks such as flexural cracks, flexural shear cracks, and compression cracks. CFRP and GFRP are light in weight and carry higher tensile strength. These fibers resist fatigue and corrosion and show good performance when subjected to tensile loads.

Being popular material for strengthening, FRP is facing the problem of reduced structural ductility and long-term durability due to reduced vapor permeability (Takewaka \& Khin, 1996; Sen, Shahawy, Rosas, \& Sukumar, 1998; Uomoto, 2001). Structural ductility is an important perimeter to be considered for structural design especially when a structure is under the influence of higher seismic forces. FRP is a brittle material and it has linear elastic behavior up to failure. In most of the cases, CFRP and GFRP have tensile failure strain ranging from 1.5 to 2\% (Saleem at al., 2015; Teng \& Lam, 2003; Watanable, Nakamura, Honda, Toyoshima, Iso, \& Fujimaki, 1997). At the failure strain, FRP's do not show any signs of distress or warning and suddenly breaks and loses all of its strength. This behavior for concrete structures is not desirable, as it does not give any kind of early warning before failure and can result in the structural hazard.

In the recent past, different researchers have numerically simulated the behavior of FRP strengthened reinforced concrete beams. Debonding failure of FRP from the concrete surface along with some thin layer of concrete is one of the typical failures in FRP strengthened systems. The key element in FRP and concrete debonding numerical simulation was the success of considering the accurate behavior of concrete and FRP interface. FEM smeared crack approach was used by Wong \& Vecchio (2003), Teng, Lu, Ye, \& Jiang, (2004), Pham \& Al-Mahaidi (2005), Neale, Ebead, Baky, Elsayed, \& Godat, (2006), Baky, Ebead, \& Neale, (2007), and Kotynia, Baky, Neale, \& Ebead, (2008). However, they found that the FRP and concrete interface behavior is mesh sensitive and were not able to closely predict the debonding behavior. Barbato (2009) assumed the perfect bond between the concrete and FRP and used FEM based beam model. However, he was not successful to predict the debonding behavior. Smith \& Gravina (2007) used a finite difference approach and were able to closely predict the beam behavior prior to debonding of the FRP. A two-dimensional finite element model based on smeared crack approach was used by Chen, Teng \& Chen (2011) to analyze the debonding behavior of FRP strengthened concrete members. Reinforced concrete members strengthened with U-shape strips and with side strips have experienced debonding type of failure (Teng, \& Chen, 2009) whereas the reinforced concrete beams or columns strengthened with FRP wraps have shown the rupture of FRP followed by Debonding failure (Cao, Chen, Teng, Hao, \& Chen, 2005; Teng, Chen, Chen, Rosenboom, \& Lam, 2009; Kim, Quinn, Ghannoum, \& Jirsa, 2014; Mofidi, Chaallal, Benmokrane, \& Neale, 2012). Chen, Teng, Chen \& Xiao (2015) considered debonding of FRP as a dynamic problem and used time integration method to address the convergence issues of FE solutions to accurately predict the test results. Zomorodian, Belarbi \& Ayoub (2017) used the softened membrane model (SMM) to predict the shear behavior of FRP strengthened reinforced concrete membrane subjected to pure shear stresses. In his research, he considered new constitutive laws for each material of the member and found a good agreement between the analytical and experimental values. Benvenuti \& Orlando (2018) studied the detachment of FRP plates from concrete and proposed a new approach based on regularized extended Finite Element Method with a mechanism-based detachment. In the current study, mechanism-based detachment approach is utilized. The material properties are modeled for each material separately and their corresponding failure mechanisms are based upon the defined material damage criterions.

In the current experimental work, the authors also took the initiative to numerically simulate the flexural behavior of FRP strengthened beam especially when the FRP strengthening pattern and its quantity is changing. In current research work, an attempt is also made to address the performance of FRP retrofitting and strengthening techniques by gradually 
reducing the FRP reinforcement ratio from 0.0125 to 0.0033 . One of the secondary goals for aiming this research initiative is to understand the effect of FRP quantity on the structural performance of reinforced concrete beams. The current study also presents the experimental evaluation of reducing FRP ratio on the flexural performance of 1-4 scaled RC beams.

\section{Methodology}

In this research study, twelve RC beams were prepared and tested under point loading for flexure and shear response. The initial conditions of beams play a significant role in the overall strength increment of the members. However, in the current research work, the beams with identical conditions are targeted and strengthened. All of the beams were prepared using the identical material properties and have the uniform surface properties for evaluation. These beams were divided into two groups and each group contains six beams of the identical cross section but different FRP reinforcement ratios. These beams contain control samples and FRP strengthened beam samples. In case of FRP strengthened beams, CFRP and GFRP were used as strengthening materials. In order to understand the compound behavior of FRP, CFRP and GFRP, both were initially investigated. However, for the later beam tests, only CFRP was used to strengthen the RC beams as it has shown better performance compared to GFRP. Different layout and reinforcement ratios were considered for these beams and tested under similar conditions to have a comparison among various retrofitting schemes. In Group-1, all beams have $100 \mathrm{~mm} \times 200 \mathrm{~mm}$ cross section with an overall length of $1200 \mathrm{~mm}$ (details are given in Table 1) while in case of Group-2 each beam has the $100 \mathrm{~mm} \times 100 \mathrm{~mm} \times 900 \mathrm{~mm}$ dimensions (Table 2). The size of beams in Group-2 was kept $100 \times 100 \mathrm{~mm}$. Due to the difficulties in placement of steel bars the only depth of the section was reduced from $200 \mathrm{~mm}$ to $100 \mathrm{~mm}$ which resulted in the rectangular shape of the beams in Group- 2 . The samples CFRP-TF+SS and CFRP-0.5TF+SS were prepared to see the effect of further reduction in tensile reinforcement while keeping the shear reinforcement constant, the sample of CFRP-0.5TF+SS was prepared which has half of the tensile FRP reinforcement compared to CFRP-TF+SS sample. In the majority of strengthening cases, it is very hard to strengthen the compression face of the beams. However, in order to make sure the tensile failure of the Group2 beams, it was decided to strengthen the compression face as well. Moreover, instead of providing the strips in 100 $\mathrm{mm}$ depth, a straight longitudinal strip is provided throughout the length of the beam for Group-2 beams. Table 1, 2 and Figure 1-2 give the details of tested beam specimens and their strengthening details.

Each of the samples in the both groups was retrofitted with different FRP reinforcement ratios (cross-sectional area of FRP / cross-sectional area of beams). FRP strip thickness was kept constant $(0.5 \mathrm{~mm})$ throughout the series of experiments and reinforcements ratios were changed by changing the FRP strip width and its application layout. FRP was applied over the surface of concrete using wet layup method and FRP reinforcement ratio was the main design parameter for each group. To have an easy application of FRP strips and to avoid disturbance and complexity in scaled properties of the model beams, the current experimental program did not consider any mechanical anchorage of the strengthened beams.

Table 1. Beam samples tested in Group-1. Source: Self elaboration.

\begin{tabular}{|c|c|c|c|}
\hline Sr \# & Sample description & Designation & $\begin{array}{l}\text { FRP } \\
\text { Reinforcement } \\
\text { ratio } \rho_{v}\end{array}$ \\
\hline 1 & Control sample without any FRP reinforcement & Control & 0 \\
\hline 2 & $\begin{array}{l}\text { Beam strengthened with GFRP on all three faces } \\
\text { except compression face }\end{array}$ & GFRP-FW & 0.0125 \\
\hline 3 & $\begin{array}{l}\text { Beam strengthened with CFRP on all three faces } \\
\text { except compression face }\end{array}$ & CFRP-FW & 0.0125 \\
\hline 4 & Beam strengthened with CFRP only at tensile face & CFRP-TF & 0.0025 \\
\hline 5 & $\begin{array}{l}\text { Beam having CFRP only at tensile face and FRP shear } \\
\text { strips on the sides }\end{array}$ & CFRP-TF+SS & 0.0045 \\
\hline 6 & $\begin{array}{l}\text { Beam having CFRP reinforcement half of sample } 4,5 \\
\text { at tensile face and FRP shear strips on the sides }\end{array}$ & CFRP-0.5TF+SS & 0.0033 \\
\hline
\end{tabular}




\begin{tabular}{|c|c|c|c|}
\hline Sr \# & Sample description & Designation & $\begin{array}{l}\text { FRP } \\
\text { Reinforcement } \\
\text { ratio } \rho_{v}\end{array}$ \\
\hline 1 & Control sample without any FRP reinforcement & Control & 0 \\
\hline 2 & Control sample without any FRP reinforcement & Control & 0 \\
\hline 3 & Beam strengthened with GFRP on all sides of beam & GFRP-FW & 0.02 \\
\hline 4 & Beam strengthened with CFRP on all sides of beam & CFRP-FW & 0.02 \\
\hline 5 & $\begin{array}{l}\text { Beam strengthened with } 50 \% \text { of GFRP reinforcement } \\
\text { on all sides of beam }\end{array}$ & GFRP-0.5W & 0.01 \\
\hline 6 & $\begin{array}{l}\text { Beam strengthened with } 50 \% \text { of CFRP reinforcement } \\
\text { on all sides of beam }\end{array}$ & CFRP-0.5W & 0.01 \\
\hline
\end{tabular}

\section{Material Properties}

Figure 1 and 2 describe the details of the samples and their strengthening plan. Reinforced concrete beams were prepared using C-28 concrete with flexural reinforcement of deformed $13 \mathrm{~mm}$ nominal diameter rebars having $\mathrm{f}_{\mathrm{y}}=420$ $\mathrm{MPa}$ as shown in Figure 1. To have the flexure failure as the dominant mode of failure, the steel reinforcement ratio in the beam samples was kept 0.016 which is lesser than the maximum tensile steel reinforcement ratio of a tension controlled section (0.026) as advised by $\mathrm{ACl} 318-08$ (2008). The concrete was obtained from a ready mixed concrete plant located in Hofuf, Saudi Arabia. The average compressive strength of the concrete was found $28.5 \mathrm{MPa}$ determined by using ASTM C39. The concrete slump was determined using ASTM C 143 was found $100 \mathrm{~mm}$. Concrete samples are compacted using a laboratory vibrator. Samples were cured in the open air to simulate the environmental conditions of their prototypes. Biaxial type of CFRP and GFRP with a fabric thickness of $0.5 \mathrm{~mm}$ was used for the entire strengthening scheme. Sikadur 330 epoxy was used for bonding FRP to the concrete surface using a plastic trowel. A careful application was ensured by maintaining a uniform epoxy coat over the concrete surface and samples were further cured for 2 days after the application.

Figure 1. Details of sample tested in Group-1 (a) Control sample, (b) CFRP-FW and GFRP-FW, (c) CFRP-TF, (d) CFRP-TF+SS, (e) CFRP-0.5TF+SS. Source: Self elaboration.

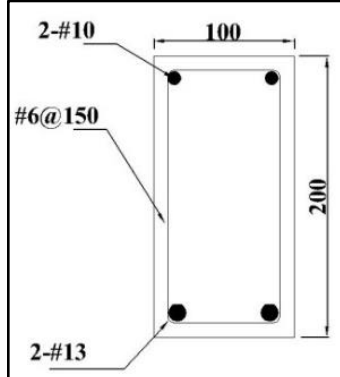

(a)

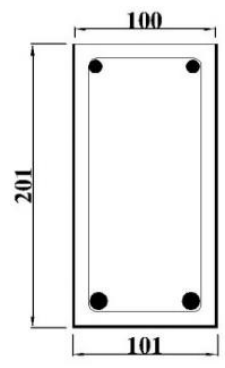

(b)

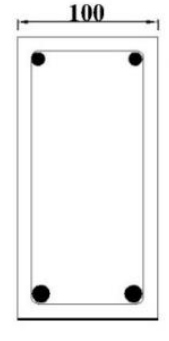

(c)

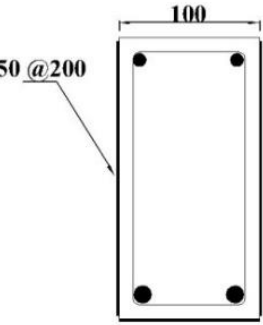

(d)

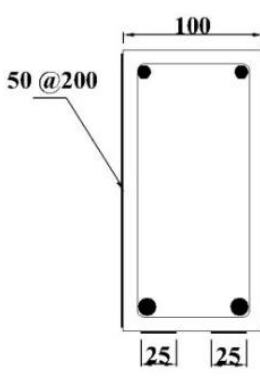

(e)

Figure 2. Details of sample tested in Group-2 (a) Control sample, (b) CFRP-FW and GFRPFW, (c) CFRP-0.5W and GFRP-0.5W. Source: Self elaboration.

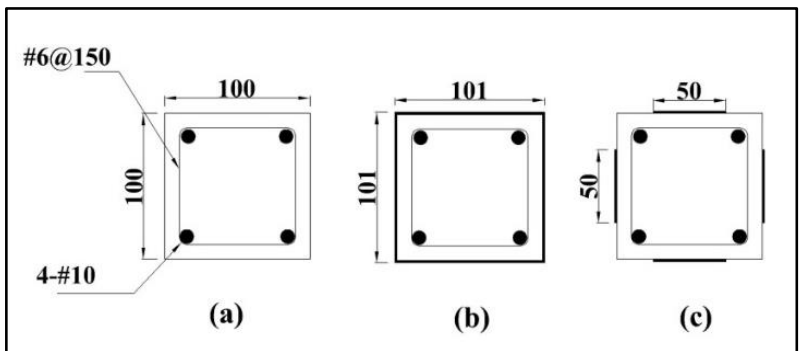

\section{Scale Factors}

Beams were scaled down using true replica modeling principles given by Noor \& Boswell (1992). Table 3 gives the dimensions of the beam model compared to that of its corresponding prototypes along with the scale factors used for geometric scaling of prototype beam with the only exception of the steel reinforcement bar due to the well-known 
problems associated with the scaling of reinforcement bars such as bond strength and minimum spacing requirement of the rebars. However, the quantity of steel reinforcement for flexure is scaled down based upon the dimension of scaled beams. The scaled beams were designed for the tension controlled failure as per ACl 318-08 (2008) and required reinforcement is provided in the form of two deformed $13 \mathrm{~mm}$ nominal diameter rebar as shown in Figure 1(a). Table 4 provides the scale factors to get the required force and deformation effects of prototypes from the values obtained from the testing and numerical simulations of the scaled beams. The size and strength of the beam samples were decided based upon the available testing facility which resulted in some deviation from the true model.

\begin{tabular}{|c|c|c|c|c|c|}
\hline & & & $\begin{array}{l}\text { Model } \\
\text { value }\end{array}$ & $\begin{array}{c}\text { Prototype } \\
\text { value }\end{array}$ & $\begin{array}{l}\text { Scale } \\
\text { factor }\end{array}$ \\
\hline & \multicolumn{2}{|c|}{ Beam Span (m) } & 1.2 & 5.0 & 4.2 \\
\hline$\geqq$ & \multicolumn{2}{|c|}{ Width (m) } & 0.1 & 0.3 & 3.0 \\
\hline$\stackrel{d}{E}$ & \multicolumn{2}{|c|}{ Depth (m) } & 0.2 & 0.45 & 2.63 \\
\hline @ & \multicolumn{2}{|c|}{ Length (m) } & 0.9 & 3.6 & 4.2 \\
\hline & \multicolumn{2}{|c|}{ Compressive strength (MPa) } & 21 & 20 & 0.95 \\
\hline$\underset{c}{\stackrel{t}{c}}$ & \multicolumn{2}{|c|}{ Shear strength $(\mathrm{kPa})$} & 0.78 & 0.76 & 0.97 \\
\hline$\stackrel{0}{\stackrel{ \pm}{\leftrightarrows}}$ & \multicolumn{2}{|c|}{ Density $\left(\mathrm{kg} / \mathrm{m}^{3}\right)$} & 2400 & 2400 & 1.0 \\
\hline & & \multicolumn{4}{|c|}{ Modeling factor } \\
\hline \multicolumn{2}{|c|}{ Physical quantity } & Relationship & True model & Curr & t study \\
\hline \multicolumn{2}{|c|}{ Length (L) } & $\mathrm{S}_{\mathrm{L}}=\mathrm{LP}_{\mathrm{P}} / \mathrm{L}_{\mathrm{M}}$ & 4 & & 2 \\
\hline \multicolumn{2}{|c|}{ Specific Mass $(\gamma)$} & $S_{Y}=\gamma_{P} / \gamma_{M}$ & 1 & & 0 \\
\hline \multicolumn{2}{|c|}{ Force $(F)$} & $S_{F}=S_{L}^{2} S_{f}$ & 64 & & 5.8 \\
\hline \multicolumn{2}{|c|}{ Displacement (d) } & $S_{d}=S_{L}$ & 4 & & 2 \\
\hline \multicolumn{2}{|c|}{ Strain $(\varepsilon)$} & $\mathrm{S}_{\varepsilon}=\varepsilon_{\mathrm{P}} / \varepsilon_{\mathrm{M}}$ & 1 & & 00 \\
\hline \multicolumn{2}{|c|}{ Strength (f) } & $S_{f}=f_{P} / f_{M}=S_{L}$ & 4 & & 95 \\
\hline \multicolumn{2}{|c|}{ Acceleration (a) } & $S_{a}=S_{f} /\left(S_{L} S_{Y}\right)$ & 1 & & 23 \\
\hline \multicolumn{2}{|c|}{ Velocity (v) } & $\mathrm{S}_{\mathrm{V}}=\left(\mathrm{S}_{\varepsilon} \mathrm{S}_{\mathrm{f}} / \mathrm{S}_{\mathrm{\gamma}}\right)^{0.5}$ & 2 & & 02 \\
\hline \multicolumn{2}{|c|}{ Frequency $(\omega)$} & $S_{\omega}=1 / S_{t}$ & 0.5 & & 25 \\
\hline \multicolumn{2}{|c|}{ Time $(t)$} & $S_{t}=S_{L}\left(S_{\varepsilon} S_{Y} / S_{f}\right)^{0.5}$ & 2 & & 00 \\
\hline
\end{tabular}

\section{Test Setup}

Figure 3(a) and (b) show experimental and schematic tests setups of beams respectively. Experiments were carried out using bending test setup available at Concrete Laboratory of King Saud University, Riyadh. Effective span of the beam was maintained at $1000 \mathrm{~mm}$ shown in Figure 3(a) and (b). Two metal plates were used to apply load over the beams. Beams were tested under a single point loading at mid-span of the beam under a displacement control system. Displacement or deflection response of the beam was measured at three points underneath the beam with the help of three LVDT's located at mid and quarter span of the beam. Data was recorded with the help of a digital acquisition system at a sampling frequency of $100 \mathrm{~Hz}$. Crack spotted during the tests were carefully marked with the loading values at which a particular crack has occurred. For the current study, the global failure of the strengthened system and the behavior of different FRP retrofitted specimen were in focus so no strain gauges were used. 


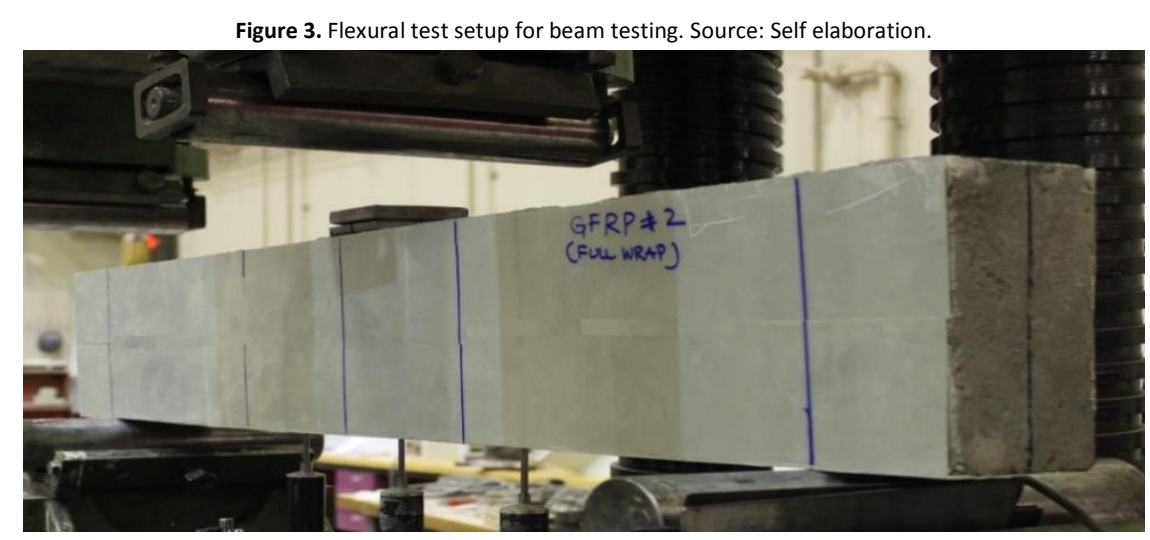

(a) Experimental Test Setup

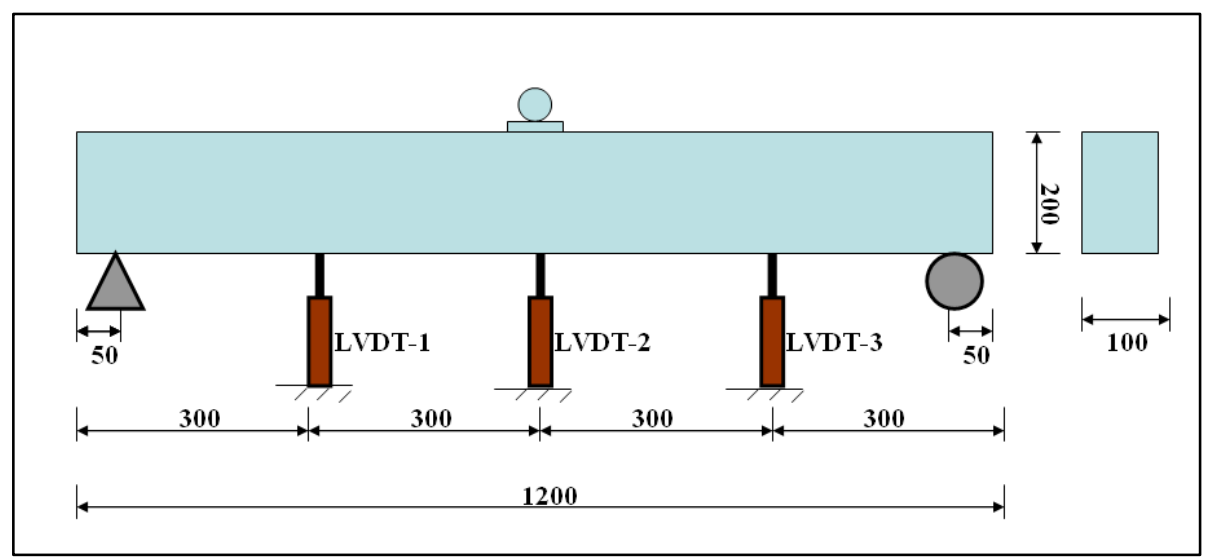

(b) Schematic Test Setup (all dimensions are in $\mathrm{mm}$ )

Figure 4 shows the load versus midspan deflection curves of all beams tested under the category of Group-1. Figure $4 a$ shows the load vs deflection curves of the control sample and fully wrapped beams whereas Figure $4 \mathrm{~b}$ gives the loaddeflection curves for those samples which have reduced CFRP reinforcement ratio. The control sample has shown a maximum of $44.1 \mathrm{kN}$ peak load value at a displacement of $6 \mathrm{~mm}$. After showing this peak load, the control sample started losing its stiffness and load starts decreasing, which shows the failure conditions of the sample. Sample completely strengthened with GFRP (GFRP+FW) has shown not much increase in strength and has shown a peak load value of $48.5 \mathrm{kN}$ which is not a significant increment in the beam strength. This lower increase in sample strength is due to the lesser contribution of GFRP material. As an equal amount of tensile strain is transferred to both CFRP and GFRP through the composite action of epoxy and concrete, the GFRP having lesser tensile and shear stiffness could not exhibit a significant increase in the beam strength. Whereas due to the higher stiffness of CFRP, CFRP-FW beam has shown a peak load value of $79.2 \mathrm{kN}$ which is approximately double the strength of the control sample. Figure $4 \mathrm{~b}$ shows the load and mid-span deflection curves for beam strengthened with CFRP but with reduced FRP volume as compared to CFRPFW. Sample CFRP-TF having CFRP strips only on the tension face has increased the control sample strength from 44.1 $\mathrm{kN}$ to $50.7 \mathrm{kN}$. This increase in beam strength was also not significant but still higher than the GFRP-FW beam sample. When FRP shear strips were added on sides (as in case of CFRP+TF strengthened beam), it increased the load carrying capacity from $49 \mathrm{kN}$ to $59 \mathrm{kN}$ which is approximately 1.5 times the strength of the control sample. In the case of CFRP$0.5 T F+S S$, tension face reinforcement is reduced by $50 \%$ which had an adverse effect on the beam strength as compared to CFRP-TF+SS strengthened beam sample. The peak load in the case of CFRP-0.5TF+SS was reported as $48.1 \mathrm{kN}$, which was slightly less than the peak load of the CFRP-TF strengthened sample. It shows that the presence of CFRP on the tensile face plays a vital role in the strength increment of the beams. The behavior of CFRP-FW beam was slightly different than the other strengthened beams. The CFRP-FW sample has undergone a higher amount of load and stored a significant amount of energy. However, as the failure of the beam happened due to debonding, the beam has lost most of it strength and its load carrying capacity has dropped from $79.2 \mathrm{kN}$ to $40.1 \mathrm{kN}$ whereas for the other samples the failure was gradual. 
Figure 4. Load-mid span deflection curves for beams samples tested under Group-1(a) for Control, CFRP-FW and GFRP-FW beam samples (b) for CFRP-TF, CFRP-TF+SS and CFRP-0.5TF+SS beam samples. Source: Self elaboration.

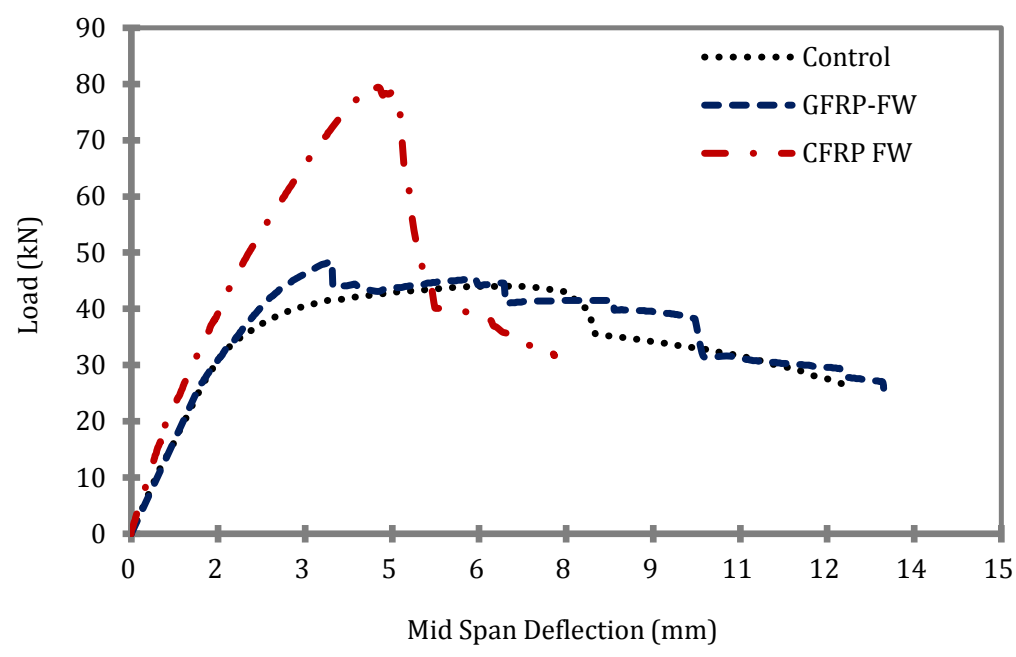

(a)

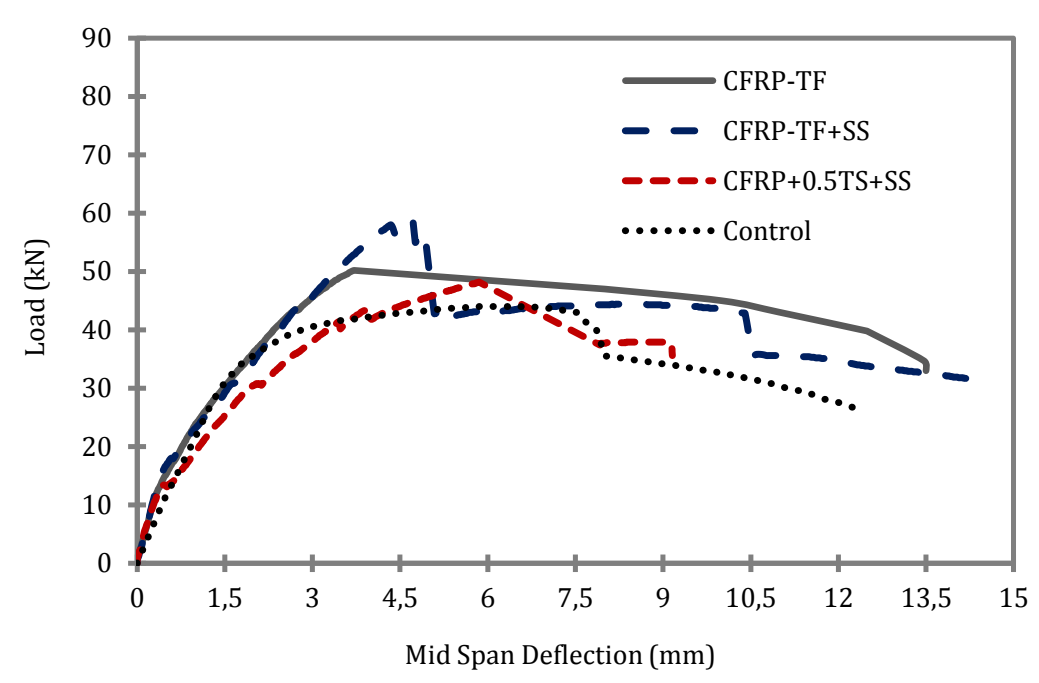

(b)

Figure 5 shows the load and deflection curves for beams tested under Group-2. Figure 5 a shows the load-deflection curves for two controlled samples, fully wrapped GFRP beam and fully wrapped CFRP beam. Both of the controlled samples having no FRP reinforcement has shown a maximum load of 12.8 and $15.7 \mathrm{kN}$ respectively at mid-span deflection value of $9 \mathrm{~mm}$. For fully wrap case, Group-2 beams have shown similar behavior as that of Group-1 as CFRP strengthened beam has shown higher peak load values as compared to GFRP strengthened beam sample. CFRP-FW has shown a peak load value of $29.3 \mathrm{kN}$ at a displacement of $4.3 \mathrm{~mm}$. The peak strength of the sample was found around two times the strength of controlled samples, however, the peak displacements were significantly lesser than the controlled sample which indicates the higher stiffness of strengthened beam samples. Whereas GFRP-FW has shown a peak load value of $21.3 \mathrm{kN}$ at a vertical displacement value of $6.2 \mathrm{~mm}$ which was higher than CFRP-FW but lesser than the control specimens.

Figure 5(b) shows the load-displacement behavior of beams when the amount of CFRP and GFRP has been reduced by half. The CFRP-0.5W and GFRP-0.5W have shown the peak strength of $17.8 \mathrm{kN}$ and $22.4 \mathrm{kN}$ at a displacement value of $6.5 \mathrm{~mm}$ and $5.3 \mathrm{~mm}$ respectively. The peak loads and deformations have been lesser than CFRP-FW and GFRP-FW strengthened samples. With the increase of further loads on CFRP-0.5W and GFRP-0.5W strengthened samples, the capacity of the beams started reducing and eventually, it became equal to the control sample at a displacement value of $15.7 \mathrm{~mm}$. 
Figure 5. Load-mid span deflection curves for beams samples tested under Group-2 (a) for Control, CFRP-FW and GFRPFW beam samples (b) for Control, CFRP-0.5FW and GFRP-0.5FW beam samples. Source: Self elaboration

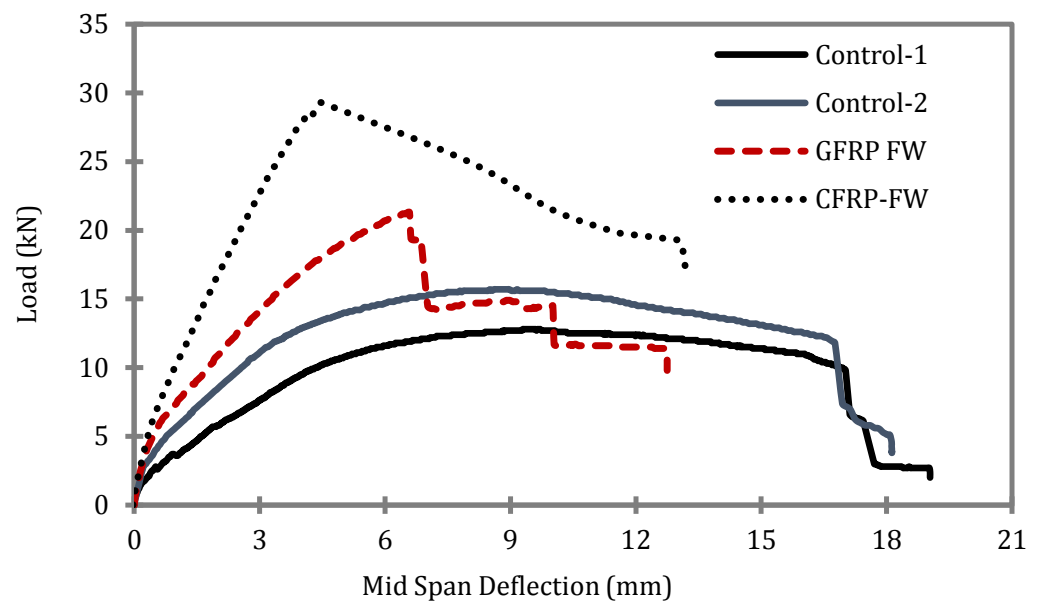

(a)

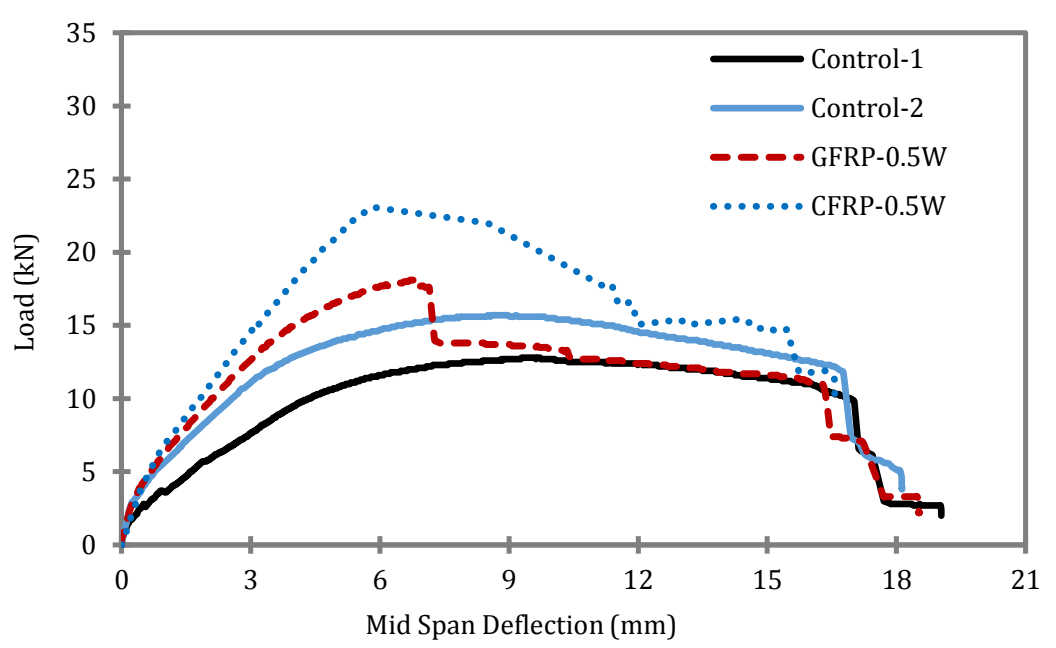

(b)

\section{Failure patterns}

Figure 6 shows the failure pattern of Group-1 beams tested under flexural loading. Figure 6a describes the failure and cracking pattern of the controlled sample observed within the middle third of the beam. The number shown on the beams are the loads at which a particular crack on beam has occurred. Figure 6a shows a flexural type of failure having a major flexural crack at $44.1 \mathrm{kN}$ which is the maximum load undergone by the sample. Figure $6 \mathrm{~b}$ shows the failure of GFRP retrofitted beam sample. Failure has occurred due to tensile rupture of GFRP sheets at the location of maximum tensile stress. Delamination of GFRP sheets was also seen on the other face of the wall. Failure of fully CFRP strengthened beam sample is given in Figure 6c. Failure in CFRP-FW is mainly debonding type of failure. No rupture of CFRP sheets was observed which shows the higher tensile strength of CFRP. Once the debonding of CFRP has occurred form the beam surface, the sample shows a decrease in peak load and started losing its strength. Debonding of CFRP has occurred due to the poor concrete surface rather than epoxy failure. Figure $6 \mathrm{~d}$ shows the cracking pattern of CFRPTF beam which has CFRP reinforcement only on the tension face. Although, the initial cracking started at a lower load level of $27.5 \mathrm{kN}$ and keep on increasing the as load further increases. Again no rupture of CFRP was observed. Figure 6e describes the failure of CFRP-TF+SS strengthened beam. Presence of shear strips has increased the load carrying capacity and changed failure pattern as the crack remained restricted within two shear strips (Figure 6e). When the CFRP tension face (TF) reinforcement is reduced by $50 \%$ with the presence of shear strips, more flexural cracks with longer distribution were observed as shown in Figure $6 \mathrm{f}$. Figure $6 \mathrm{~g}$ shows the part of the detached strip from CFRP-0.5TF+SS beam sample. No rupture of CFRP has been observed. Some part of the concrete surface can be clearly observed in Figure $6 \mathrm{~g}$ which confirms that the failure neither happened in CFRP nor in epoxy. However, the concrete surface was the governing factor for the strength increment of the beam. 
Figure 6. Failure patterns of beam samples tested under Group-1 for (a) Control sample, (b) GFRP-FW, (c) CFRP-FW, (d) CFRP-TF, (e) CFRP-TF+SS, (f) CFRP$0.5 T F+S S$ (g) CFRP detached strip. Source: Self elaboration.-

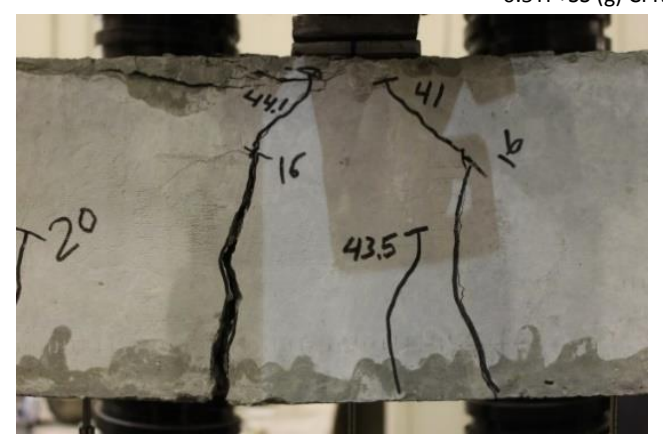

(a)

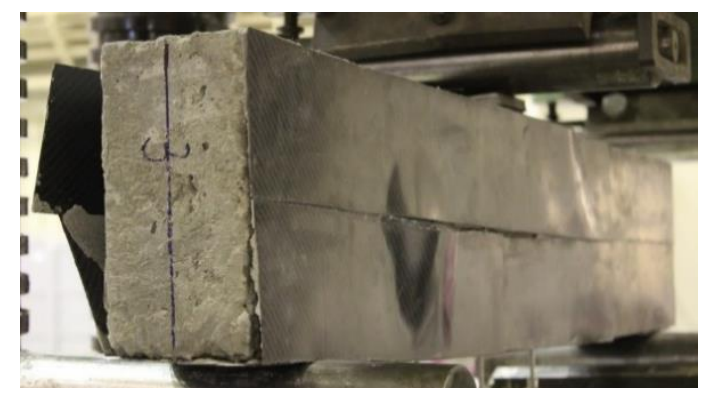

(c)

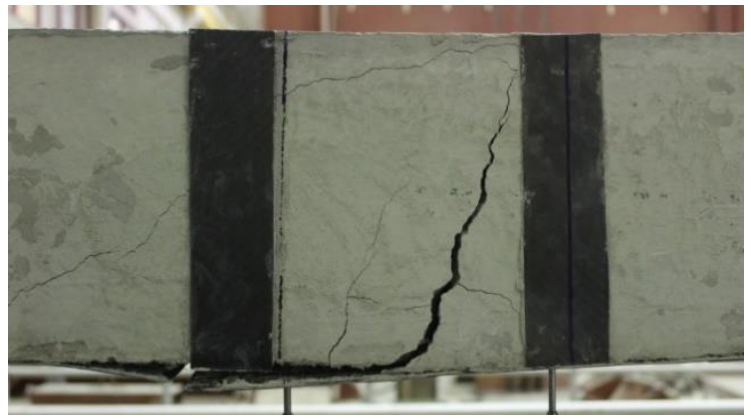

(e)

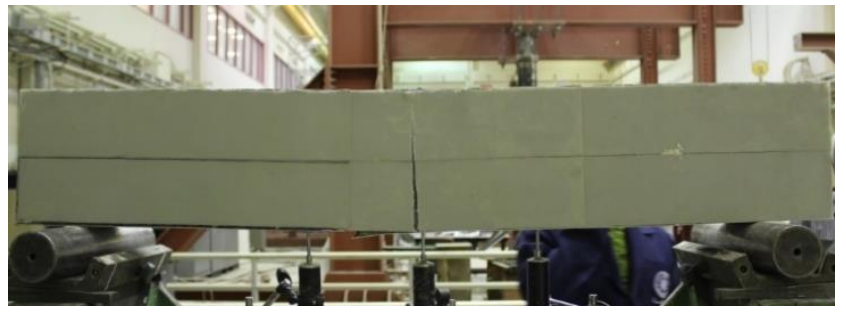

(b)

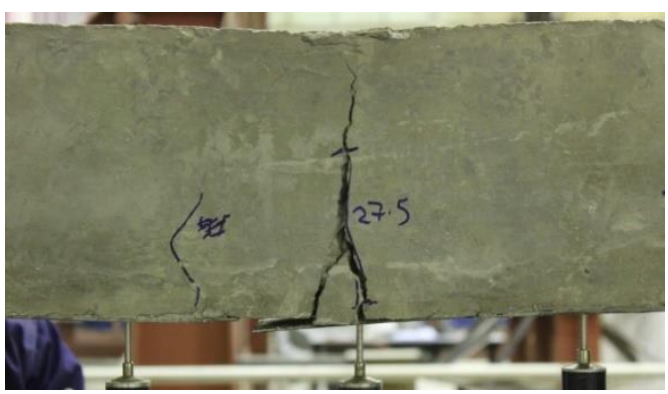

(d)

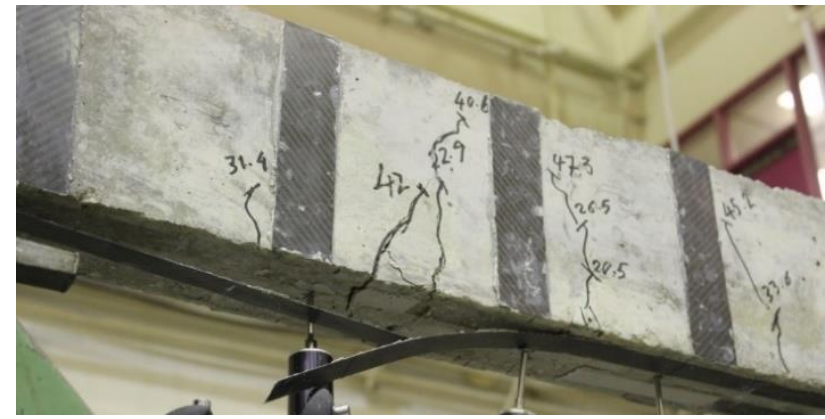

(f)

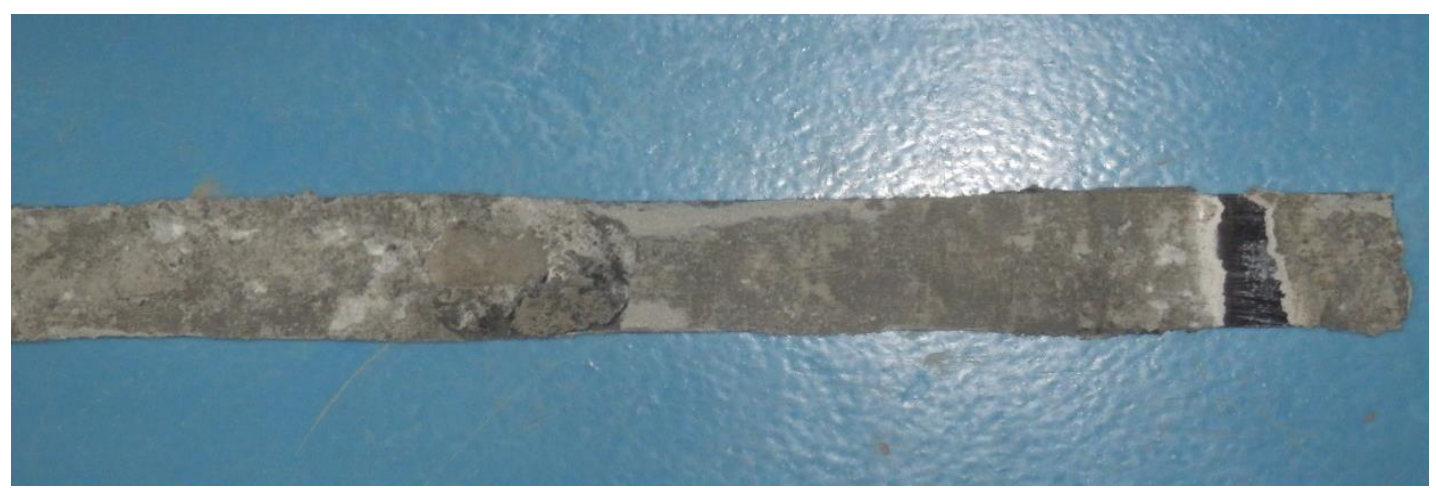

(g)

\section{Numerical simulation}

The numerical simulation was done on a Finite Element (FE) package ABAQUS which is powerful computer package and fully capable of modeling any three-dimensional problem with geometric and material non-linearities. Taking the advantage of the double symmetry of RC beam, only a quarter of beam was simulated as shown in Figure 7. 


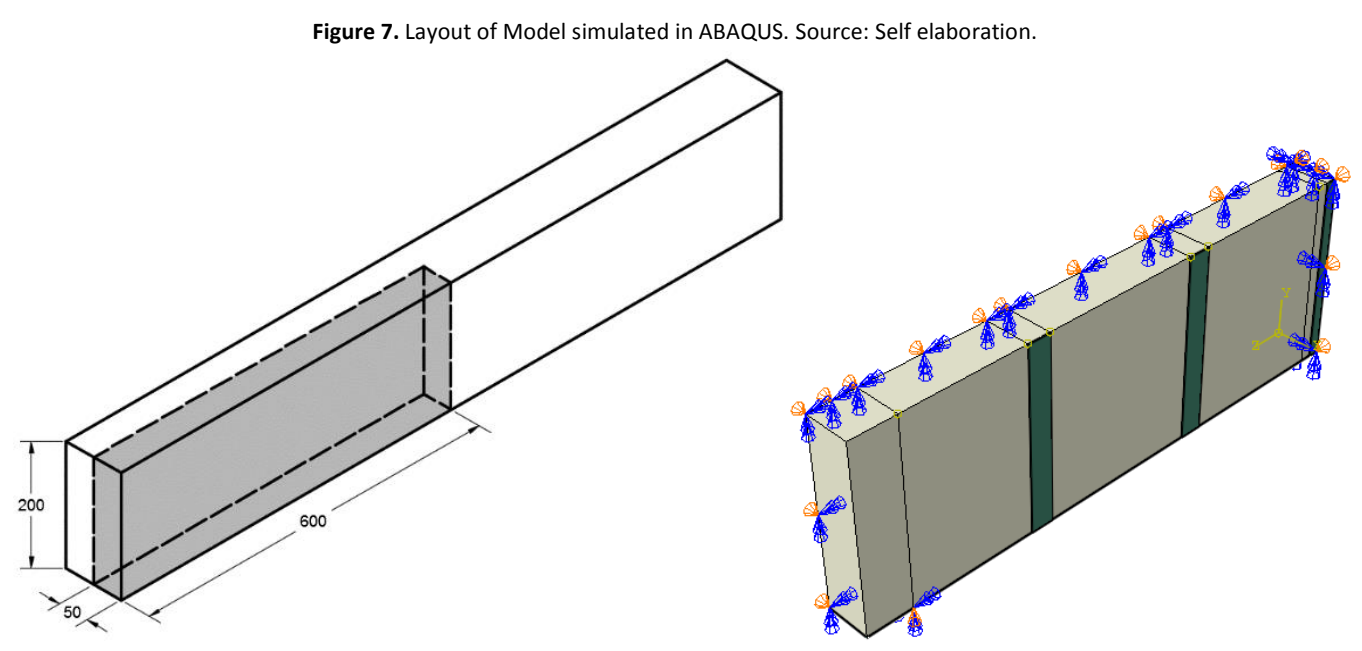

\section{Element Type and Mesh Density}

The concrete is discretized with a 3D, 8-node hexahedron solid element keeping a minimum element size of $6.25 \mathrm{~mm}$ to obtain convergence. Since only the quarter portion of the beam is simulated, the width (i.e., $50 \mathrm{~mm}$ ) of the quarter model was divided into eight equal part, making the element size $6.25 \mathrm{~mm}$ and along the length direction the mesh size is kept as $12.5 \mathrm{~mm}$. Steel is simulated using two node truss elements and is embedded in the concrete material. To represent the behavior of GFRP and CFRP, four node shell elements were considered.

To resolve the convergence problems, the load was subdivided into various steps considering the anticipated concrete cracking time. Further in each step, small enough increments ware used with automatic stabilization. The constituted model was modified by using a very small coefficient of viscosity. Through parametric analysis, a viscosity parameter equal to 0.0006 was found to be helpful to achieve the convergence with minimum computation time.

\section{Concrete behavior modeling}

Concrete behavior was modeled using the concrete damage plasticity model available in ABAQUS. This model considers the compression crushing and tensile cracking as two major failure mechanisms. In addition, the concrete damage plasticity model requires five damage parameters along with the modulus of elasticity and poison's ratio. The value of the poison's ratio is chosen as 0.2 whereas the values of other damage parameters are mentioned in Table 5 . For the uniaxial compression behavior of concrete, a linear stress-strain relationship is considered up to the $50 \%$ of peak strength $\left(f_{c}^{\prime}\right)$. The remaining compression curve is derived using the expression proposed by Carreira, \& Kuang-Han (1986) as given in Eq. (1) and (2).

$$
\begin{aligned}
\beta & =\frac{1}{1-\frac{f_{c}^{\prime}}{\varepsilon_{0} E_{c}}} \\
\frac{f_{c}}{f_{c}^{\prime}} & =\frac{\beta \cdot\left(\frac{\varepsilon}{\varepsilon_{0}}\right)}{\beta-1+\cdot\left(\frac{\varepsilon}{\varepsilon_{0}}\right)^{\beta}}
\end{aligned}
$$

Where, $\varepsilon_{0}$ and $E_{c}$ value were calculated as proposed by Ahmed (1981) and ACl-318 (2008) respectively, as given in Eq. (3) and (4) respectively.

Where:

$$
\begin{aligned}
& \varepsilon_{0}=0.001648+0.0000165 \times f_{c}^{\prime} \\
& E_{c}=4700 \sqrt{f_{c}^{\prime}}
\end{aligned}
$$

$\mathrm{f}_{\mathrm{c}}=$ the stress corresponding to the strain $\varepsilon$

$\mathrm{f}_{\mathrm{c}}{ }^{\prime}=$ the point of maximum stress, considered as the compressive strength 
$\varepsilon_{0}{ }^{\prime}=$ the strain corresponding to the maximum stress

$E_{c}=$ The modulus of elasticity of concrete

$\beta=$ a parameter that depends on the shape of the stress-strain diagram

\begin{tabular}{|c|c|c|c|c|}
\hline $\begin{array}{l}\text { Flow potential } \\
\text { eccentricity }\end{array}$ & $\begin{array}{c}\text { Dilation } \\
\text { angle }\end{array}$ & $\begin{array}{l}\text { The ratio of initial } \\
\text { equibiaxial compressive } \\
\text { yield stress to initial } \\
\text { uniaxial compressive } \\
\text { yield stress }\end{array}$ & $\begin{array}{l}\text { The ratio of the } \\
\text { second stress } \\
\text { invariant on the } \\
\text { tensile } \\
\text { meridian }\end{array}$ & $\begin{array}{l}\text { Viscosity } \\
\text { parameter }\end{array}$ \\
\hline$\epsilon$ & $\psi\left({ }^{0}\right)$ & $f_{b o} / f_{c o}$ & $K_{c}$ & $v$ \\
\hline 0.1 & 37 & 1.16 & 0.67 & 0.0006 \\
\hline
\end{tabular}

The complete stress-strain curve of concrete under uniaxial compression is presented in Figure 8 . Concrete tensile behavior is assumed as linear elastic until the initiation of cracking corresponding to tensile strength $\left(f_{t}{ }^{\prime}\right)$ that is calculated by Eq. (5). A displacement base post-cracking behavior is defined using Eq. (6) \& (7) as proposed by Murthy, Palani \& Nagesh (2009). In Eq. (6) fracture energy $\left(G_{f}\right)$ is calculated by Eq. (8) (FIB Bulletin 42 2008) and $n$ value is assumed as 3. Figure 9 illustrates the post-peak tension stiffening behavior of concrete used in the numerical study.

$$
\begin{aligned}
& f_{t}^{\prime}=0.25 \sqrt{f_{c}^{\prime}} \\
& d_{0}=G_{f} \frac{(n+1)}{f_{t}^{\prime}} \\
& f_{t}=f_{t}^{\prime} \times\left(1-\frac{x}{d_{0}}\right)^{n} \\
& G_{f}=110\left(\frac{f_{c}^{\prime}}{10}\right)^{0.18}
\end{aligned}
$$

Where:

$f_{t}=$ the tensile strength of the concrete at any strain $\varepsilon$

$f_{t}^{\prime}=$ the tensile strength of the concrete

$G_{f}=$ fracture energy

$d_{o}=$ crack width

$x=$ crack width at stress $f_{t}$

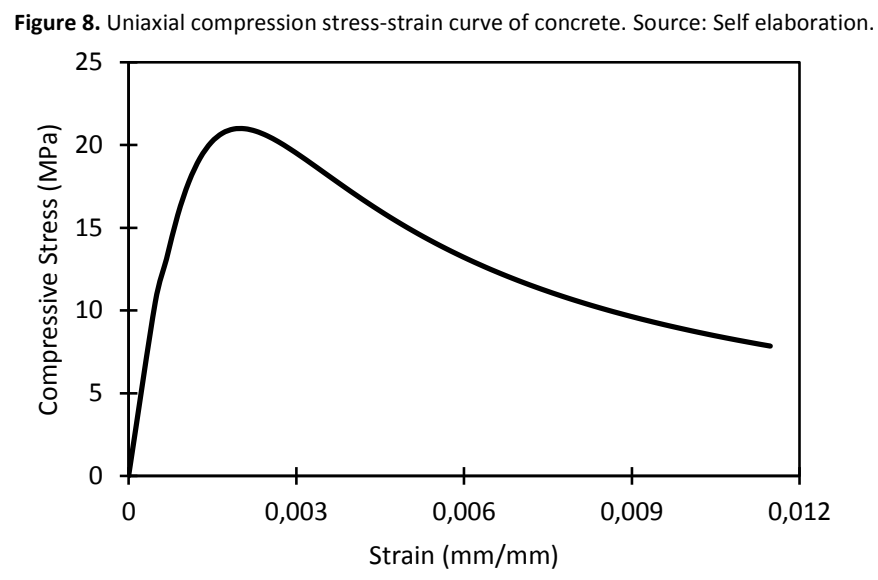

\section{Steel behavior modeling}

The reinforcing steel is simulated as elastic-perfectly plastic with isotropic strain hardening criterion. The modulus of elasticity, yield stress and poison's ratio are assumed to be 200,000 MPa, $420 \mathrm{MPa}$ and 0.3, respectively. 
Figure 9. Post-Peak tesnile behavior. Source: Self elaboration.

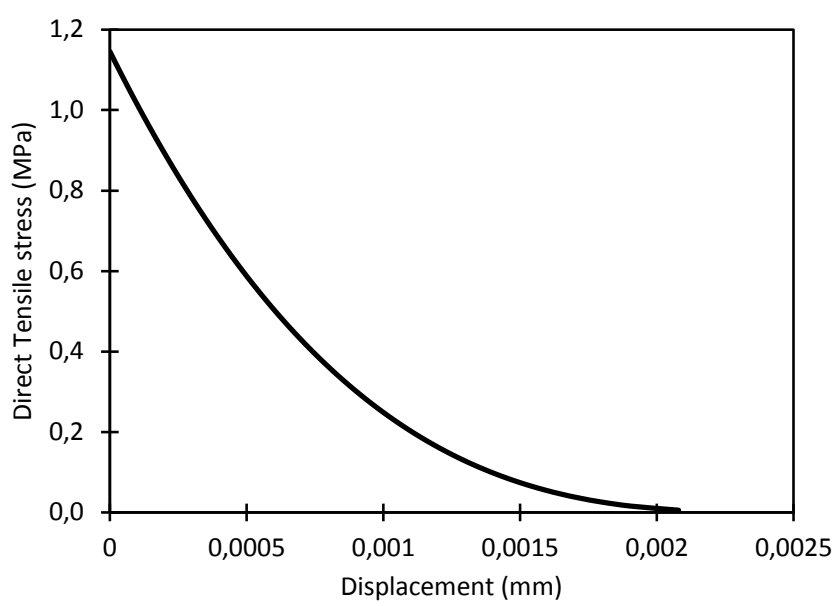

\section{FRP modelling}

Since experimental study indicates that failure occurred primarily due to the cracking of concrete without any deboning in adhesive material or rupture of FRP. Therefore, FRP is modeled as an orthotropic elastic material. For this purpose, the mechanical properties provided by the manufacturer are employed. The mechanical properties used in the study are presented in Table 6. In Table 6, $E_{1}$ and $E_{2}$ are the moduli of elasticity of FRP in direction 1 and two as illustrated in Figure 10. Whereas, $v_{12}, \mathrm{G}_{12}$ and $\mathrm{G}_{23}$ are the poison's ratio and shear modulus in their respective directions.

Figure 10. Reference axes of FRP Strip. Source: Self elaboration.

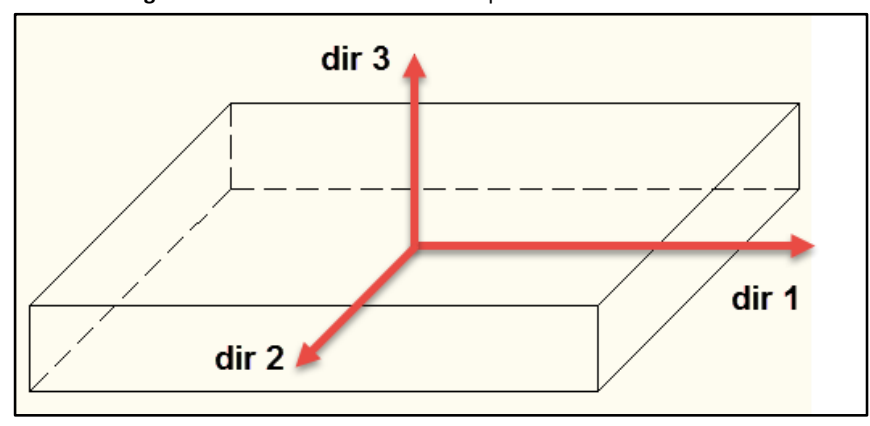

Table 6. Parameter for FRP Damage Model. Source: Self elaboration.

\begin{tabular}{lcccccc}
\hline & Tensile Strength & $E_{1}$ & $E_{2}$ & & $G_{12}=G_{21}$ & $G_{23}$ \\
Fiber Type & $(\mathrm{MPa})$ & $(\mathrm{MPa})$ & $(\mathrm{MPa})$ & $v_{12}$ & $(\mathrm{~Pa})$ & $(\mathrm{MPa})$ \\
\hline GFRP & 1100 & 45000 & $1 \times 10^{-5}$ & 0.3 & $1 \times 10^{-5}$ & 6200 \\
CFRP & 1600 & 120000 & 25000 & 0.3 & $1 \times 10^{-5}$ & 3000 \\
\hline
\end{tabular}

\section{Adhesive Interface Modelling}

ABAQUS library provides two different types of the adhesive modeling techniques e.g., defining the adhesive as a material property using adhesive elements or as surface based interaction property. The interface is modeled by using surface-based contact and cohesive behavior is defined as interaction properties. The formulae and constitution laws of surface-based cohesive behavior are very similar to the cohesive element and require a linear elastic tractionseparation, damage initiation criteria and damage evolution law.

The initial stiffness parameters are assumed same and linear in all direction (i.e., $K_{0}=K_{n}=K_{s}=K_{t}$ ) until the initiation of damage. To calculate the value of initial stiffness, the equation proposed by Guo, Cao, Sun, \& Lin, (2005) as mention in Eq. (9), was utilized. 


$$
K_{0}=\frac{1}{t_{a} / G_{a}+t_{c} / G_{c}}
$$

Where in Eq. (9)

$t_{c}=$ thickness of concrete

$t_{\mathrm{a}}=$ thickness of adhesive

$G_{c}=$ shear modulus of concrete

$G_{a}=$ shear modulus of adhesive

Quadratic traction function criteria comprising of nominal stresses as given in Eq. (10) is specified for the initiation of cohesive damage.

$$
\left(\frac{\left\langle\sigma_{n}\right\rangle}{\sigma_{n}{ }^{\mathrm{max}}}\right)^{2}+\left(\frac{\tau_{n}}{\tau_{n}{ }^{\mathrm{max}}}\right)^{2}+\left(\frac{\tau_{s}}{\tau_{s}^{\mathrm{max}}}\right)^{2}=1
$$

Here in Eq (10),

$\sigma_{\mathrm{n}}=$ cohesive tensile stress

$\tau_{n}$ and $\tau_{s}$ shear contact stresses in $\mathrm{n}$ and $\mathrm{s}$ (first and second) shear direction.

Since, failure initiated due to cracking of concrete along the adhesive layer, the maximum normal stress as suggested by researchers in similar studies (Obaidat, Heyden, \& Dahlblom, 2010), is used equal to tensile fracture stress i.e., $\sigma_{n}{ }^{\text {max }}$ $=f_{c t}=1.145 \mathrm{Mpa}$. Further, owing to the isotropic nature of adhesive material $\tau_{n}$ and $\tau_{s}$ are also used equal to $\sigma_{n}{ }^{\text {max }}$.

For surface base cohesive formulation, damage evolution is characterized by the cohesive stiffness degradation. In the present study, a total fracture energy dissipation criteria was used for the cohesive interface damage evolution.

Damage evaluation was specified as a mixed mode function using Benzaggagh-Kenane (BK) fracture model available in ABAQUS library. BK model (Eq. (11)) is useful for the isotropic materials, when critical fracture energies are the same along the first $\left(G_{t c}\right)$ and second $\left(G_{n c}\right)$ shear direction. In this study, $G_{n c}=1000 \mathrm{~J} / \mathrm{m}^{2}, G_{n c}=G_{n c}=1000 \mathrm{~J} / \mathrm{m}^{2}$ with $\eta=2.284$. Since cohesive behavior is considered isotropic $\left(G_{n c}=G_{n c}=G_{n c}=G_{T c}\right)$ and mixed mode in BK model will be independent of $\eta$ value.

$$
G_{n c}+\left(G_{s c}-G_{n c}\right)\left(\frac{G_{\text {shear }}}{G_{T}}\right)^{\eta}=G_{T C}
$$

Where,

$$
\begin{aligned}
& G_{\text {shear }}=G_{s c}+G_{t c} \\
& G_{T}=G_{n c}+G_{\text {shear }}
\end{aligned}
$$

\section{Load-Displacement Curves}

Figure 11 shows the experimental and FE-based numerical load-displacement curves of beams tested under Group-1. Control sample has shown a peak value of 44.1 and $44.4 \mathrm{kN}$ under experiment and numerical simulation respectively as shown in Figure 11(a). Numerical simulation of control reinforced concrete beam sample has shown a fair agreement with experimental results. It can also be observed that numerical load-displacement values predicted by the ABAQUS are very close to the corresponding experimental values prior to the failure of samples. However, a variation in loaddisplacement behavior could be seen in the post-peak behavior of the sample. The possible reason for this variation is a limitation of ABAQUS to follow the post-peak cracking behavior of concrete beam which is largely affected by the used damage model for the failure prediction of concrete. Figure 11(b) shows the numerical and experimental loaddisplacement behavior of concrete sample that was fully wrapped with the CFRP. The peak load determined by the numerical simulation was found lower than the experimental peak load. The possible reason could be the better surface 
behavior shown by the concrete, epoxy and FRP interface in case of tested (CFRP-FW) beam sample. In spite of the close prediction of peak load behavior in most of the concrete samples, it is not fully guaranteed to get the same peak load for all of the samples as the interface of concrete, epoxy and FRP is not certain. A small variation in concrete surface quality and non-uniform application of epoxy can significantly vary the experimental peak values from the numerically predicted loads. Both experimental and numerical peak loads are witnessed at the same displacement level of $4.74 \mathrm{~mm}$. A similar numerical and experimental stiffness of CFRP-FW sample was observed until the displacement level of $2.0 \mathrm{~mm}$ after it, the numerical model has shown significant stiffness degradation, which resulted in a smaller peak load. However, in case of the GFRP-FW strengthened beam, peak load values of the experimental and numerical model were $45.4 \mathrm{kN}$ and $49.3 \mathrm{kN}$ respectively which were very close to each other as shown in Figure 11(c). In case of CFRP-TF sample, a numerical peak load value predicted by ABAQUS is $48.2 \mathrm{kN}$ which is very close to the experimental peak load value of $50.2 \mathrm{kN}$ as shown in Figure 11(d). Similar kinds of trends were shown by the numerical simulations of CFRP-TF+SS and CFRP-0.5TF+SS strengthened samples. In case of the numerical load-displacement curve of CFRP-TF+SS retrofitted concrete beam, peak load was closer to the corresponding values but beam has not shown any residual strength as compared to experimental load-displacement curve as given by Figure 11(e). Figure 11(f) shows that the numerical peak value and post-peak behavior of CFRP-0.5TF+SS sample was similar to that of its experimental counterpart. All of the numerical load-displacement curves have shown a smooth increase and decrease in stiffness and no sudden falls in strength were observed. Prediction of the behavior remains fairly accurate until the members have reached their peak strength. However, post-peak behavior or residual deformations were not matching that of experimental values. This phenomenon is due to the inelastic behavior of cracked beam sections especially when the cracks are wide enough and concrete surfaces remain no more in contact. Sudden rise and fall in the experimental load-displacement curves were also observed, these could be due to uncertainty associated with the bonding of FRP with concrete and surface quality of concrete itself.

A comparison of experimental and numerical peak loads along of different samples along with their reinforcement ratio and the \%age difference is given in Table 7. The percentage difference is calculated by taking experimental values as reference. A positive value of percentage difference indicates a higher experimental load compared to the numerical values. All of the samples have shown a good agreement between experimental and numerical values and percentage difference remained under 10 percent except CFRP-FW. It motivates to further explore the damage prediction model of FRP, especially when the FRP is present on compression side with a higher value of tensile stiffness as the existing model has predicted a close behavior to experimental values when CFRP was applied only on the tensile face with or without FRP shear strips.

Figure 11. Comparison of Experimental and Numerical FEM Load-displacement curves (a) Control sample, (b) CFRP-FW, (c) GFRP-FW, (d) CFRP-TF, (e) CFRP-TF+SS, (f) CFRP-0.5TF+SS. Source: Self elaboration.

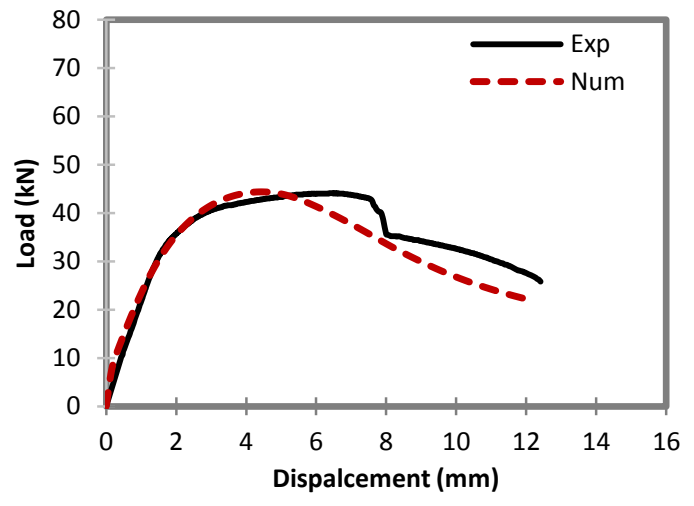

(a) Control Sample

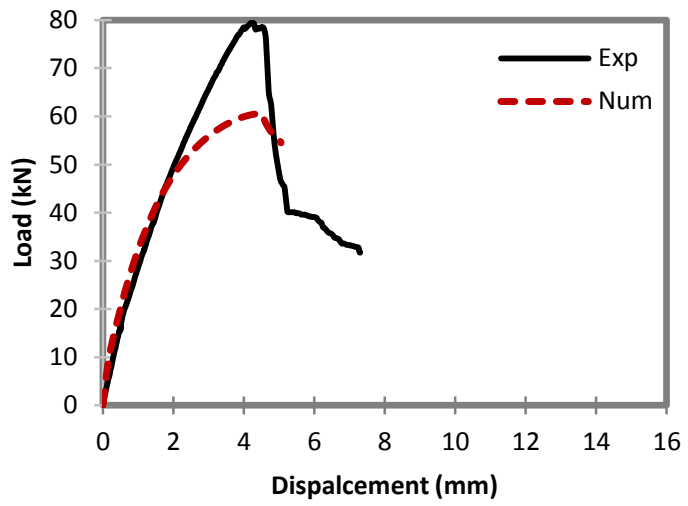

(b) CFRP-FW 


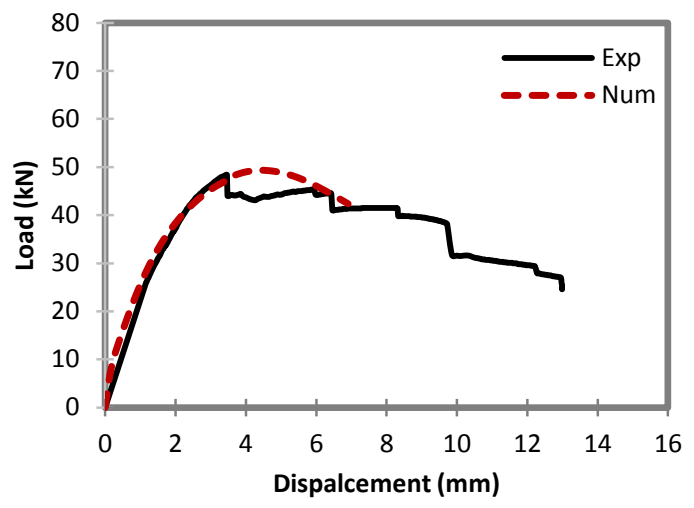

(c) GFRP-FW

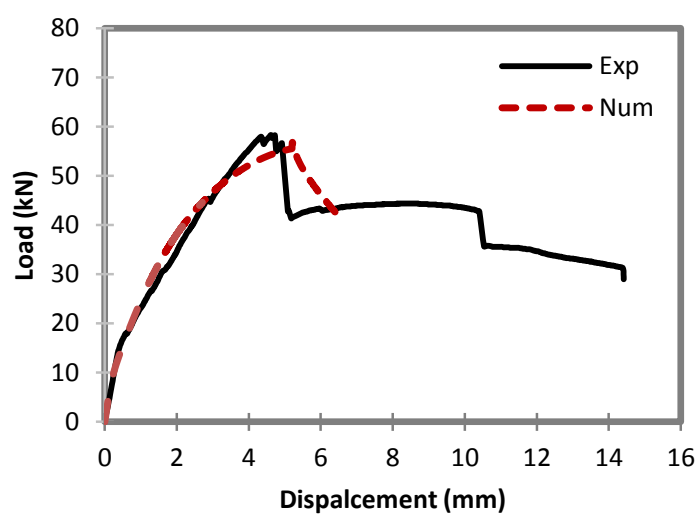

(e) CFRP-TF+SS

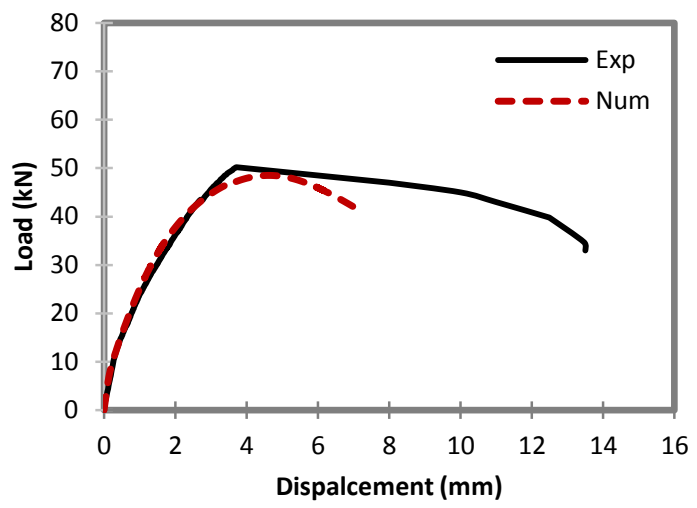

(d) CFRP-TF

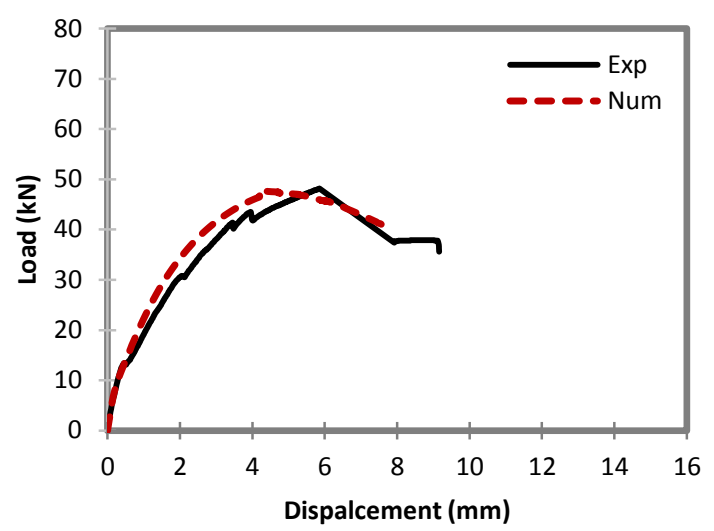

(f) CFRP-TF+0.5SS

Table 7. Summary of numerical simulation results. Source: Self elaboration

\begin{tabular}{llcccc}
\hline Sr \# & Designation & $\rho_{v}$ & $P_{\operatorname{Exp}}(k N)$ & $P_{\text {Num }}(k N)$ & \%age Diff \\
\hline 1 & Control & 0 & 44.1 & 44.4 & -0.7 \\
2 & CFRP-FW & 0.0125 & 79.4 & 54.5 & 31.4 \\
3 & GFRP-FW & 0.0125 & 45.4 & 49.3 & -8.6 \\
4 & CFRP-TF & 0.0025 & 50.2 & 48.5 & 3.4 \\
5 & CFRP-TF+SS & 0.0045 & 57.2 & 54.7 & 4.4 \\
6 & CFRP-0.5TF+SS & 0.0033 & 47.4 & 47.7 & -0.6 \\
\hline
\end{tabular}

\section{Cracks Initiation}

Due to the limitation of concrete damage plasticity in grasping the crack pattern at material integration points, the maximum principal plastic strain criteria is often used to investigate the cracks evolution in FE analysis (Lubliner, Oliver, Oller, \& Oñate, 1989). For this purpose, it is considered that the cracks develop, where maximum principal strain is positive. Figure 12 describes the location of heavily stressed and cracked parts of tested samples under the Group-1 category. The strain contours in Figure 12 are shown for quarter part of the beam at the inner face of concrete located near the center of the beam along the length. In case of a control sample, the central tensile zone has shown the peak values of strain 0.008 as shown in Figure 12(a). These strain contours for the control sample are plotted at a displacement range of $4.00 \mathrm{~mm}$ and peak load of $42 \mathrm{kN}$. From the strain contours, pure flexural cracks can be observed with higher concentrations of strain near the bottom central part and these values reduce as the distance from the center of beam increases. Figure 12(b) and (c) shows the cracking pattern of beams fully wrapped with CFRP and GFRP respectively. The strain contours are plotted at a displacement interval of $4.70 \mathrm{~mm}$ and $5.0 \mathrm{~mm}$ respectively just prior to the post-peak behavior of retrofitted beam samples. Both samples have shown the strain concertation near quarter spans. It is also observed that beams are stressed throughout the length and across the depth of the sections, which 
shows an effective utilization of beam section for strength contribution. The locations of highest strain concentrations are the ones where debonding of CFRP and GFRP first started. The FE model as shown in Figure 12 (d) for CFRP-TF, also reveals the debonding due to the cracking of concrete at the location of maximum tensile stress. CFRP-TF and control samples have shown the similar location of strain concentration except for the values of strains. Presence of CFRP at tensile face only has increased the strain values near the tension face of the beam. Flexural mode of failure remains dominant throughout the length of testing and a wider crack was observed at the mid-span of the beam. By adding side CFRP strips in addition to CFRP on the tensile face has improved the flexural behavior and reduced the stress concentration as shown in Figure 12(e). However, debonding of CFRP from tensile face remain the dominant parameter of failure. It could be seen from Figure $12(f)$ that as the amount of CFRP strips was reduced by half, the plastic strain values further increased and load carrying capacity of the beam has reduced.

Figure 12. Numerical FE based strain contours of (a) Control sample, (b) CFRP-FW, (c) GFRP-FW, (d) CFRP-TF, (e) CFRP-TF+SS, (f) CFRP-0.5TF+SS. Source: Self elaboration.

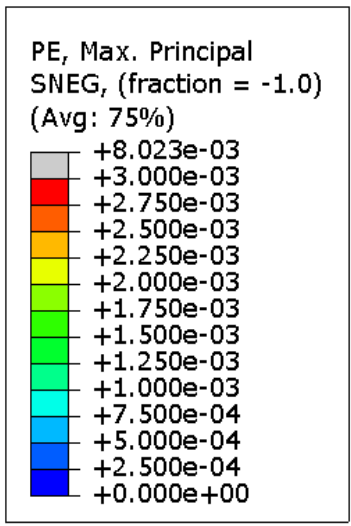

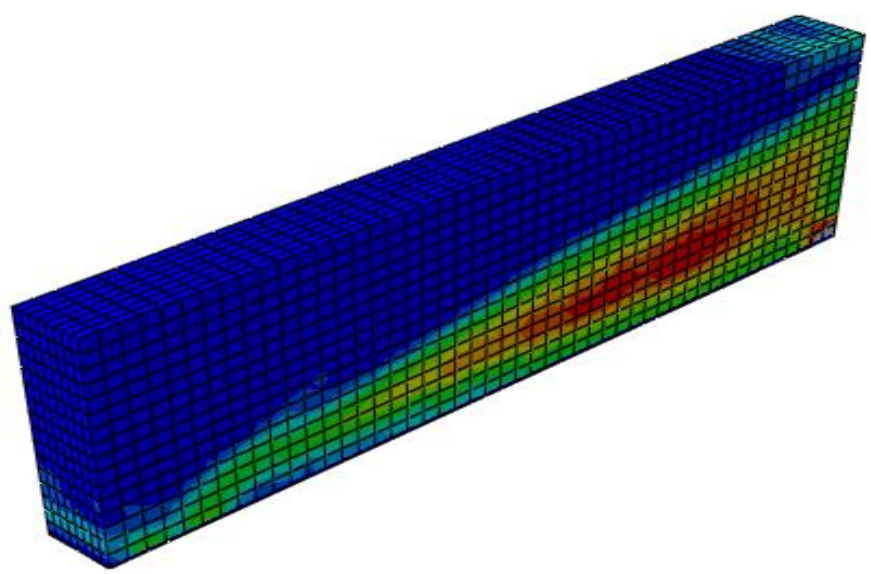

(a) Control Sample

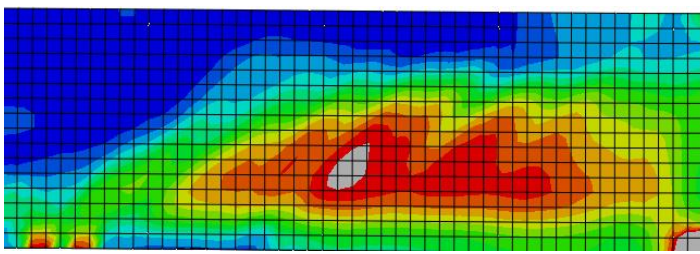

(b) CFRP-FW

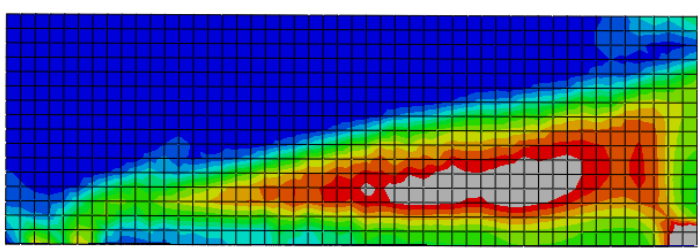

(d) CF-TF only

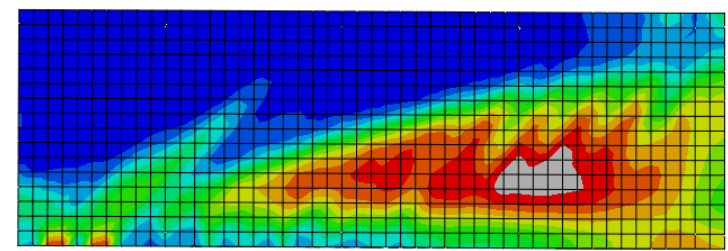

(c) GFRP-FW

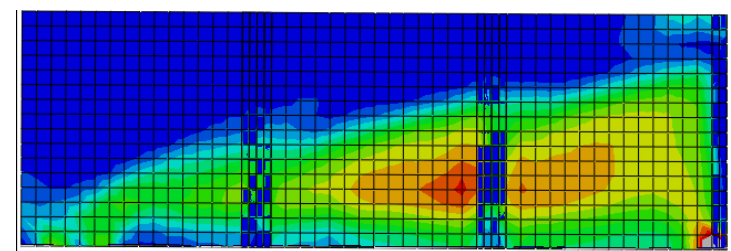

(e) CF-TF+ SS

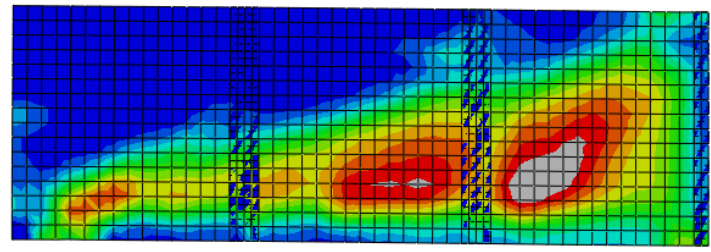

(f) $\mathrm{CF}-\mathrm{TF}+0.5 \mathrm{SS}$ 
Current research work has given an opportunity to study the effect of various FRP reinforcements layouts and their ratios. FRP reinforcement ratio, FRP strip width, beam cross-section and type of FRP fiber were the parameters under study.

Test results have clearly indicated that CFRP is much more effective than GFRP as it has shown a higher increase in beam flexural strength. Due to lesser tensile strength, GFRP has very less effect on strength increment. For both of the beam groups, strength increment was almost double as compared to their control samples when CFRP was used as strengthening material and applied on all the surfaces of beams. Use of FRP at tension face only (without side strips) is not recommended or careful analysis should be performed to skip shear strengthening. In case of beam strengthened in Group-2, it has been found that decrease in strength was almost proportional to decrease in FRP reinforcement and same was found true for both CFRP and GFRP strengthened beams panels. After observing the failure patterns, it has been found that rupture of FRP was observed only in case of GFRP strengthened beam panels. In case of CFRP strengthened beam panels, failure was initiated due to debonding of FRP from the beam surface. This debonding was either due to epoxy failure or due to poor concrete surface quality then cracks propagated in the beams until complete fracture. Peak Load obtained by the FE analysis are close to that of corresponding experimental values but the postpeak behavior was not accurately predicted. Hence it is required to further investigate the FRP and epoxy existing debonding models to accurately predict the inelastic behavior especially when the concrete members are bearing wide and deep cracks.

\section{Acknowledgments}

This research was supported by the Deanship of Scientific Research (DSR) at King Faisal University (KFU) through its "Eighteenth Annual Research Project no. 180061." The authors are thankful for the Department of Civil Engineering, College of Engineering and Deanship of Scientific Research for providing the required support in terms of the material purchase, sample preparations and testing. Authors are also thankful to Concrete Laboratory, Department of Civil and Environmental Engineering, King Saud University for their technical support.

References

Ahmed, S.H. (1981). Properties of confined concrete subjected to static and dynamic loading (Ph.D. Thesis). University of Illinois at Chicago, USA

American Concrete Institute (ACI) Committee 318. (2008). Building Code requirement for structural concrete and commentary (ACl 318-08). Farmington Hills, MI 48331, USA.

Baky, H. A., Ebead, U.A. \& Neale, K.W. (2007). Flexural and interfacial behavior of FRP strengthened reinforced concrete beams. Composites for Construction, 11(6), 629-639.

Barbato, M. (2009). Efficient finite element modelling of reinforced concrete beams retrofitted with fiber reinforced polymers. Computer and Structures, 87(3-4), 167-176.10.1016/j.compstruc.2008.11.006.

Benvenuti, E. \& Orlando, N. (2018). Intermediate flexural detachment in FRP-plated concrete beams through a 3D mechanism-based regularized extended Finite Element Method. Composites Part B, 145(1), 281-293.

Cao, S.Y., Chen, J.F., Teng, J.G., Hao, Z. \& Chen, J. (2005). Debonding in RC beams shear strengthened with complete FRP wraps. Composites for Construction, 9, 417-428.

Carreira, D.J. \& Kuang-Han, C. (1986). Stress-strain relationship for reinforced concrete in tension. ACl Structural Journal, 83(3), 21-28.

Chajes, M.J., Jansuska,T.F., Mertz, D.R., Thomson, T.A., \& Finch Jr., W.W. (1995). Shear strength of RC beams using externally applied composite fabrics. ACl Structural Journal, 92(3), 295-303.

Chen, G.M., Teng, J.G. \& Chen, J.F. (2011). Finite-element modelling of intermediate crack debonding in FRP-plated RC beams. Journal of Composites for Construction, 15(3), 339-353.

Chen, G.M., Teng, J.G., Chen, J.F. \& Xiao, Q.G. (2015). Finite element modeling of debonding failures in FRP-strengthened RC beams: A dynamic approach. Computers \& Structures, 158(1), 167-183.

Chen, J.F., \& Teng, J.G. (2003). Shear capacity of FRP strengthened RC beams: FRP debonding. Construction and Building Material, 17(1), 27-41.

Deniaud, C., \& Cheng, J.J.R. (2004). Simplified shear design method for concrete beams strengthened with fiber reinforced polymer sheets. Journal of Composites for Construction, 8(5), 425-433.

Eshwar, N., Nanni, A., \& Ibell, T.J. (2008). Performance of Two Anchor Systems of Externally Bonded Fiber-Reinforced Polymer Laminates. ACI Materials Journal, 105(1), 72-80.

Guo, Z.G., Cao, S.Y., Sun, W.M., \& Lin, X.Y. (2005). Experimental study on bond stress-slip behaviour between FRP sheets and concrete. In proceedings of the International Symposium on Bond Behavior of FRP in Structures. Hong Kong, China. 
International Federation for Structural Concrete Bulletin (FIB). (2008). Constitutive modelling of high strength / high performance concrete, State-ofart report 42, International Federation for Structural Concrete, Lausanne.

Khalifa, A., \& Nanni, A. (2000). Improving shear capacity of existing RC T-section beams using CFRP composites. Cement \& Concrete Composites, 22(1), 165-174.

Kim, Y., Quinn, K., Ghannoum, W.M. \& Jirsa, J.O. (2014). Strengthening of reinforced concrete T-beams using anchored CFRP materials. ACI Materials Journal, 111(a), 1027-1035.

Kotynia, R., Baky, H. A., Neale, K. W., \& Ebead, U. A. (2008). Flexural strengthening of RC beams with externally bonded CFRP systems: Test results and 3D nonlinear FE analysis. Composites for Construction, 12(2), 190-201.10.1061/(ASCE)1090-0268(2008)12:2(190).

Lubliner J., Oliver J., Oller S., \& Oñate, E. (1989). A plastic-damage model for concrete. International Journal of Solids Structures 25(1); 299-329.

Mofidi, A., Chaallal, O., Benmokrane, B. \& Neale, K. (2012). Performance of end-an- chorage systems for RC beams strengthened in shear with epoxybonded FRP. Composites for Construction, 16, 322-331.

Murthy, R.C., Palani, G.S. \& Nagesh, R.I. (2009). State-of-the-art review on fracture analysis of concrete structural components. Sadhana, 34(2), 345367

Neale, K. W., Ebead, U. A., Baky, H. M. A., Elsayed, W. E., \& Godat, A. (2006). Analysis of the load-deformation behaviour and debonding for FRPstrengthened concrete structures. Advances in Structural Engineering, 9(6), 751-763.10.1260/136943306779369437.

Noor, F.A. \& Boswell, L. F. (1992). Small Scale Modelling of Concrete Structures. Elsevier applied Science Publishers Ltd. London.

Obaidat, Y.T., Heyden, S. \& Dahlblom, O. (2010). The effect of CFRP and CFRP/concrete interface models when modelling retrofitted RC beams with FEM. Composite structure, 92(1), 1391-1398.

Pham, H. B. \& Al-Mahaidi, R. (2005). Finite element modelling of RC beams retrofitted with CFRP fabrics. 7th Int. Symp. on Fiber-Reinforced (FRP) Polymer Reinforcement for Concrete Structures (ACI Symp. Publication 230). (pp. 499-513). Kansas City, MO.

Saleem, M. U., Numada, M., Amin, M. N., \& Meguro, K. (2016). Shake Table Tests on FRP Retrofitted Masonry Building Models. Journal of Composites for Construction, 20(5), 1-19.

Saleem, M. U., Numada, M., Amin, M. N., \& Meguro, K. (2015). Fiber Reinforced Polymer and Polypropylene Composite Retrofitting Technique for Masonry Structures. Journal of Polymers, 7(1); 963-984.

Sen, R. Shahawy, M., Rosas, J. \& Sukumar, S. 1998. Durability of aramid pretensioned elements in a marine environment. ACl Structural Journal, 95(5), 578-587.

Smith, S. T., \& Gravina, R. J. (2007). Modeling debonding failure in FRP flexurally strengthened RC members using a local deformation model. Journal of Composites for Construction, 11(2), 184-191.10.1061/(ASCE)1090-0268(2007)11:2(184)

Sulaimani, G.J., Shariff A., Basanbul, I.A., Baluch, M.H., \& Ghaleb, B.N. (1994). Shear repair of reinforced concrete by fiber glass plate bonding. ACI Structural Journal, 91(4), 458-464.

Takewaka, K. \& Khin, M. (1996). Deterioration and stress rupture of FRP rods in alkaline solution simulating a concrete environment. Proceedings of 2nd International Conferences on Advanced Composite Materials in Bridges and Structures, Winnipeg, Canada. Canadian Society of Civil Engineers, Winnipeg.

Teng, J. G. \& Lam, L. (2003). Design-oriented stress-strain model for FRP-confined concrete. Construction and Building Materials, 17(1), 471-489.

Teng, J. G., Lu, X. Z., Ye, L. P., \& Jiang, J. J. (2004). Recent research on intermediate crack-induced debonding in FRP-strengthened RC beams. Proc., 4th Int. Conf. Advanced Composite Materials in Bridges and Structures, ACMBS IV, M. El-Badry and L. Dunaszegi, eds. (pp. 1-12). Calgary, Alberta, Canada

Teng, J.G. \& Chen, J.F. (2009). Mechanics of debonding in FRP-plated RC beams. Proc. Inst. Civil Eng.-Struct. Build. 162, 335-345.

Teng, J.G., Chen, G.M., Chen, J.F., Rosenboom, O.A. \& Lam, L. (2009). Behavior of RC Beams Shear Strengthened with Bonded or Unbonded FRP Wraps. Composites for Construction, 13, 394-404.

Triantafillou, T.C. 1998. Shear strengthening of reinforced concrete beams using epoxy bonded FRP composites. ACI Structural Journal, 95(2), 107115.

Triantafillou, T.C., \& Antonopoulos, C.P. (2000). Design of concrete flexural members strengthened in shear with FRP. Journal of Composites for Construction, 4(4), 198-205

Uomoto, T. (2001). Durability of FRP reinforcement as concrete reinforcement. Proceedings of International Conferences on FRP composites in Civil Engineering. (pp.85-97). Hong Kong, China.

Watanable, K., Nakamura, H., Honda, T., Toyoshima, M., Iso, M. \& Fujimaki, T. (1997). Confinement effect of FRP sheet on strength and ductility of concrete cylinders under uniaxial compression. In: Non-Metallic (FRP) Reinforcement for Concrete Structures. Japan Concrete Institute. Proceedings of the Third International Symposium, vol. 1. (pp. 233-240). Sapporo, Japan.

Wong, R. S. Y \& Vecchio, F. J. (2003), Toward modeling of reinforced concrete members with externally bonded fiber-reinforced polymer composites ACl Structural Journal, 2003;100 (1):47-55.

Zomorodian, M., Belarbi, A. \& Ayoub, A. (2017). Finite element model for predicting the shear behavior of FRP-strengthened RC members. Engineering Structures, 153(1), 239-253. 